DOI: 10.18499/2225-7357-2019-8-2-15-21

УДК 611.132

14.03.01 - анатомия человека

(C) Коллектив авторов, 2019

\title{
Сравнительная характеристика морфометрических параметров брюшной аорты и ее непарных ветвей У мужчин с различным типом телосложения
}

\author{
П. М. Быков ${ }^{1}$, И. В. Гайворонский ${ }^{2,3}$, М. Г. Гайворонская 3,4, Г. И. Синенченко 2 \\ ${ }^{1}$ ФГАОУ ВО «Белгородский государственный национальный исследовательский \\ университет», Белгород, Россия \\ 2ФГБВОУ ВО «Военно-медицинская академия им. С.М. Кирова», Санкт-Петербург, Россия \\ зФГБОУ ВО «Санкт-Петербургский государственный университет», Санкт-Петербург, \\ Россия \\ 4ФГБУ «Национальный медицинский исследовательский центр им. В.А. Алмазова» Минздрава \\ России, Санкт-Петербург, Россия
}

Цель - изучить особенности морфометрических параметров брюшной части аорты и ее непарных ветвей у взрослых мужчин с различным типом телосложения.

Материал и методы. Проведен анализ 148 компьютерных томограмм брюшной части аорты и ее непарных ветвей у взрослых мужчин в возрасте 25-75 лет с различным типом телосложения. Согласно классификации В.Н. Шевкуненко, были выделены три группы с долихоморфным, мезоморфным и брахиморфным типами телосложения. Согласно значению индекса Пинье, выделены астенический, нормостенический и гиперстенический типы телосложения.

Результаты. Установлено, что диаметр брюшной аорты на уровне чревного ствола не различается в зависимости от типа телосложения по В.Н. Шевкуненко, в группах, выделенных по индексу Пинье, диаметр брюшной аорты различается на всех уровнях. Длина брюшного отдела аорты имеет достоверные различия только между крайними формами телосложения - долихо- и брахиморфной, а также между гипер- и астениками. При использовании индекса В.Н. Шевкуненко из изученных угловых параметров достоверно отличается только угол отхождения верхней брыжеечной артерии, в группах, систематизированных по значению индекса Пинье, различия наблюдаются по всем угловым параметрам.

Заключение. В связи с тем, что классификация В.Н. Шевкуненко отражает в большей степени линейные параметры тела, а индекс Пинье - еще и объемные (обхват груди, массу тела), последний обеспечивает большее количество различий сравниваемых параметров брюшной аорты и ее непарных ветвей, в том числе, зависящих от типа и степени развития абдоминальной жировой клетчатки.

Ключевые слова: брюшная аорта, непарные ветви брюшной аорты, классификация В.Н. Шевкуненко, индекс Пинъе, тип телосложения.

Comparative Characteristics of the Morphometric Parameters of the Abdominal Aorta and its Unpaired Branches in Men with Different Body Types

(C) P. M. Bykov ${ }^{1}$, I. V. Gaivoronskii², 3, M. G. Gaivoronskaya3, 4, G. I. Sinenchenko², 2019

${ }^{1}$ Belgorod State National Research University, Belgorod, Russia

${ }^{2}$ Military Medical Academy named after S.M.Kirov, Saint-Petersburg, Russia

3 St. Petersburg State University, Saint-Petersburg, Russia

4Almazov National Medical Research Centre, Saint-Petersburg, Russia

The aim of the study was to determine characteristics of the morphometric parameters of the abdominal part of aorta and its unpaired branches in adult men with different body types.

Material and methods. An analysis of 148 computer tomograms of the abdominal aorta and its unpaired branches was carried out in adult men aged 25-75 years with a different body type. According to the classification V.N. Shevkunenko, three groups with dolichomorphic, mesomorphic and brachymorphic types were distinguished. According to the Pigne Index, asthenic, normostenic and hypersthenic body types are distinguished.

Results. It was established that the diameter of the abdominal aorta at the level of the celiac trunk does not differ depending on the body type according to V.N. Shevkunenko, in groups identified by the Pigne index, the diameter of the abdominal aorta differs at all levels. The length of the abdominal aorta has significant differences only between extreme forms of body type - dolicho- and brachymorphic, as well as between hyper and asthenic. When using the index V.N. Shevkunenko from the studied angular parameters reliably differs only the angle of discharge of the superior mesenteric artery, in groups systematized by the Pigne index, differences are observed in all angular parameters.

Conclusion. Due to the fact that the classification of V.N. Shevkunenko reflects to a greater degree the linear parameters of the body, and the Pigne index is also voluminous (chest girth, body weight), the latter provides a greater number of differences in the compared parameters of the abdominal aorta and its unpaired branches, including those depending on the type and degree of development of the abdominal fatty tissue.

Key words: abdominal aorta, unpaired branches of the abdominal aorta, V.N. Shevkunenko classification, Pigne index, body type. 
*Автор для переписки:

Быков Петр Михайлович

ФГАОУ ВО «Белгородский государственный национальный исследовательский университет», ул. Победы, 85, г. Беогород, 308015, Российская Федерация.

E-mail: bpm.aibolit@mail.ru

* Corresponding author:

Petr Bykov

Belgorod State National Research University, ul. Pobedy, 85, Belgorod, 308015, Russian Federation

E-mail: bpm.aibolit@mail.ru

\section{Введение}

Основным источником кровоснабжения органов брюшной полости и забрюшинного пространства являются ветви брюшной аорты. Брюшная аорта располагается на передней поверхности позвоночника несколько левее срединной плоскости, на уровне IV поясничного позвонка она делится на правую и левую общие подвздошные артерии $[4,9,15]$. Непарными ветвями брюшной части аорты являются: чревный ствол, верхняя и нижняя брыжеечные артерии. Устье чревного ствола располагается на уровне нижнего края XII грудного позвонка, что совпадает примерно с верхним краем поджелудочной железы [11]. Однако описаны случаи его отхождения на уровне верхнего края I поясничного позвонка $[2,3]$.

Уровень отхождения верхней брыжеечной артерии (ВБА) варьирует и может находиться на участке от XII грудного позвонка до межпозвоночного диска между I-II поясничными позвонками [8, 12]. По данным большинства авторов, нижняя брыжеечная артерия (НБА) отходит на уровне нижнего края III поясничного позвонка [7]. S. Sinkeet et al. [14] указывают, что в 91.4\% случаев она начинается между LII-LIV позвонками.

Следует отметить, что в литературе сведения об основных морфометрических параметрах брюшной части аорты и ее непарных ветвей представлены недостаточно подробно $[5,9,11]$. В основном приводятся данные об их изменении в зависимости от пола и возраста $[10,16-18]$.

Часть работ посвящена изучению особенностей анатомии указанного сосудистого бассейна у лиц различных национальностей $[9,13,14]$.

В ряде работ освещены изменения сосудистой морфологии ветвей брюшной аорты после оперативных вмешательств [19].

Единичные работы по изучению конституциональных особенностей аорты [6] ограничены лишь ее основным стволом без указания морфометрических параметров непарных ветвей. При этом, как отмечают Е.А. Анисимова и соавт. [1], изучение морфометрических особенностей отдельных органов должно обязательно проводиться во взаимосвязи с особенностями внешних параметров тела человека, поскольку существующие корреляции между конституциональными особенностями тела человека и строением внутренних органов имеют важное диагностическое значение в различных отраслях медицины. Подобных работ в проанализированной нами отечественной и зарубежной литературе не обнаружено.

Цель исследования - изучить особенности морфометрических параметров брюшной части аорты и ее непарных ветвей у взрослых мужчин с различным типом телосложения.

\section{Материал и методы исследования}

Исследование проводилось в период с 2015 по 2019 год в отделении лучевой диагностики областной клинической больницы Святителя Иоасафа (учебная база кафедры госпитальной хирургии медицинского института НИУ БелГУ), г. Белгород. Исследование одобрено независимым Этическим комитетом при Военно-медицинской академии имени C.М. Кирова (протокол № 192 от 18.07.2017 г.).

Для анализа были отобраны результаты КТ-исследований органов брюшной полости, выполненные мужчинам в возрасте от 25 до 75 лет с целью исключения неопластических процессов абдоминальной зоны, уточнения характера доброкачественных образований в печени (кисты, гемангиомы), диагностики заболеваний почек и надпочечников. Пациенты после хирургических вмешательств на органах брюшной полости (включая операции на сосудах), с хроническими заболеваниями ЖКТ, печени, поджелудочной железы в исследование не включались.

Bce пациенты давали письменное информированное добровольное согласие на проведение исследования.

Согласно классификации типов телосложения по методике В.Н. Шевкуненко (1935), все исследованные мужчины были разделены на три группы: I группа - с долихоморфным; II - с мезоморфным; III - с брахиморфным типами телосложения. Индекс телосложения вычисляли как отношение длины туловища к длине тела, умноженное на 100\%. Значение индекса телосложения менее 28,5 соответствовало долихоморфному типу; более 31,5 - брахиморфному типу; остальные значения указанного индекса были характерны для обладателей мезоморфного типа.

Наряду с этим, также использовали индекс Пинье, являющийся показателем крепости телосложения. Индекс определяли по формуле:

$$
\text { Индекс Пинье = } \mathrm{P}-(\mathrm{M}+\text { ОГК), }
$$

где $\mathrm{P}$ - рост человека, М - масса тела; ОГК объем грудной клетки в покое. М.В. Черноруцкий (1929) величины этого индекса использовал для определения типа конституции. Согласно его классификации, у нормо- 
стеников индекс Пинье равен 10-30, астеников - больше 30, гиперстеников - меньше 10.

По значению индекса Пинье, все обследованные мужчины были разделены нами также на три группы: I группа - с астеническим; II - с нормостеническим; III - с гиперстеническим типами телосложения.

Исследуемым проводили мультисрезовую спиральную компьютерную томографию на компьютерном томографе «Aquilion 64" фирмы «Toshiba», Япония. Внутривенное контрастирование осуществлялось с помощью автоматического шприца-инжектора, который обеспечивал введение йодсодержащего контрастного препарата с концентрацией йода 370 мг/мл со скоростью 4.5 мл/с. Процедура сканирования проводилась по стандартной методике, в том числе, в артериальную фазу контрастирования (через 5 с после достижения пиковой концентрации контрастного вещества в аорте на уровне диафрагмы). Толщина реконструктивного среза получаемых изображений составляла 0.5 мм.

Анализ полученных данных осуществлялся на индивидуальной компьютерной рабочей станции врача-рентгенолога «Vitrea 4.3» с использованием специализированного программного пакета для изучения сосудистой системы (Vascular: Aorta CT). Морфометрические данные (длина сосудов, углы их отхождения, диаметр и т. д.) получали в наиболее репрезентативных для каждого параметра проекциях (двухмерной, криволинейной, мультипланарной, проекции максимальной интенсивности, объемном рендеринге).

Статистическая обработка полученных данных осуществлялась с использованием пакета прикладных программ Statistica 7.0. Для каждого признака определяли: среднее арифметическое значение и ошибку среднего арифметического. Для выявления значимости различия между средними величинами определяли t-критерий Стьюдента.

\section{Результаты и их обсуждение}

Анализ результатов исследования показал, что статистически достоверные различия у мужчин долихо-, мезо- и брахиморфного типов имеются по 11 изученным параметрам.

Диаметр брюшной аорты на уровне чревного ствола не имеет типовых особенностей, в то время как ее поперечный диаметр на уровне 5 мм проксимальнее устьев почечных артерий в среднем на 1.7 мм больше у лиц брахиморфного типа по сравнению с долихоморфным, а поперечный диаметр аорты на уровне 5 мм проксимальнее бифуркации аорты в среднем имеет разницу в 1.3 мм между крайними группами.

Максимальных значений диаметр чревного ствола достигает у брахиморфов. Диа- метр селезеночной артерии и наибольший диаметр НБА статистически достоверно различаются только между крайними типами телосложения: первый параметр - на 0.4 мм, второй - на о.6 мм. В то же время диаметр левой желудочной артерии имеет достоверные различия также между группами долихои мезоморфов, а также брахи- и мезоморфов. Диаметр общей печеночной артерии и наибольший диаметр ВБА не имеют статистически достоверных различий между выделенными группами. Однако при этом наибольшая разница в диаметре ВБА на уровне 5 мм дистальнее устья подвздошно-ободочнокишечной артерии наблюдается между мезои брахиморфами (о.5 мм) (табл. 1).

Что касается длины изученных сосудов, то длина брюшного отдела аорты имеет достоверные различия только между крайними формами телосложения - долихо- и брахиморфной. Так, у последних значения данного показателя составляют $157.2 \pm 2.4$ Mм, в то время как у первых - лишь 148.0 \pm 2.0 мм, что в среднем на 9.2 мм меньше.

Длина основного ствола НБА также достоверно больше у брахиморфов по сравнению с другими типами телосложения. Различия в значениях данного показателя составляют 13.5 мм между крайними формами. При этом длина чревного ствола и длина основного ствола ВБА типовых особенностей не имеют.

Расстояние между центрами устьев нижней брыжеечной и дистальнее расположенной почечной артерии достигает наибольших значений у долихоморфов. Его средние значения в данной группе составляют $63.7 \pm 2.3$ мм, в то время как у брахиморфов $56.5 \pm 1.5$ мм. Расстояние между центром устья НБА и бифуркацией аорты имеет обратную динамику. Так, его средние значения в группе долихоморфов на 5.9 мм меньше, чем у брахиморфов.

Следует отметить, что из изученных угловых параметров достоверно отличается только угол отхождения ВБА, а угол отхождения чревного ствола не имеет выраженных типовых особенностей.

При изучении особенностей морфометрических параметров брюшной аорты и ее непарных ветвей в группах, систематизированных по значению индекса Пинье, установлено, что 17 из изученных параметров имеют типовые особенности (табл. 2).

Установлено, что по индексу Пинье диаметр брюшной аорты на разных уровнях статистически достоверно изменяется в зависимости от типа телосложения. В среднем на уровне чревного ствола, на уровне 5 мм проксимальнее устьев почечных артерий и на уровне 5 мм проксимальнее бифуркации аорты разница между крайними типами (астеническим и гиперстеническим) составляет 2.4 MM. 
Таблица 1

Морфометрическая характеристика брюшной аорты и ее непарных ветвей у мужчин с различными типами телосложения по классификации В.Н. Шевкуненко, $(\mathrm{M} \pm \mathbf{m})$

\begin{tabular}{|c|c|c|c|}
\hline \multirow[b]{2}{*}{ Морфометрические параметры } & \multicolumn{3}{|c|}{ Типы телосложения } \\
\hline & $\begin{array}{c}\text { Долихоморфный } \\
\mathrm{n}=34\end{array}$ & $\begin{array}{c}\text { Мезоморфный } \\
\mathrm{n}=38\end{array}$ & $\begin{array}{c}\text { Брахиморфный } \\
\mathrm{n}=42\end{array}$ \\
\hline $\begin{array}{l}\text { Диаметр аорты на уровне чревного } \\
\text { ствола, мм }\end{array}$ & $22.9 \pm 0.6$ & $23.1 \pm 0.6$ & $23.8 \pm 0.3$ \\
\hline $\begin{array}{l}\text { Поперечный диаметр аорты на уровне } \\
5 \text { мм проксимальнее устьев почечных } \\
\text { артерий (либо устья проксимальнее } \\
\text { распложенной почечной артерии), мм }\end{array}$ & $20.1 \pm 0.5$ & $21.0 \pm 0.6$ & $21.8 \pm 0.3^{*}$ \\
\hline $\begin{array}{l}\text { Поперечный диаметр аорты на уровне } \\
5 \text { мм проксимальнее бифуркации аор- } \\
\text { ты, мм }\end{array}$ & $17.3 \pm 0.3$ & $18 \pm 0.5$ & $18.6 \pm 0.3^{*}$ \\
\hline Длина брюшного отдела аорты, мм & $148 \pm 2.0$ & $152.1 \pm 2.3$ & $157.2 \pm 2.4^{*}$ \\
\hline Длина чревного ствола, мм & $25.1 \pm 0.9$ & $26.4 \pm 0.9$ & $27.1 \pm 0.9$ \\
\hline $\begin{array}{l}\text { Наибольший диаметр чревного ство- } \\
\text { ла, мм }\end{array}$ & $7.7 \pm 0.2$ & $8.1 \pm 0.2$ & $8.3 \pm 0.2^{*}$ \\
\hline Угол отхождения чревного ствола, ${ }^{\circ}$ & $34.6 \pm 3.0$ & $41.6 \pm 2.2$ & $41.0 \pm 2.7$ \\
\hline $\begin{array}{l}\text { Диаметр левой желудочной артерии, } \\
\text { мм }\end{array}$ & $3.4 \pm 0.1^{* *}$ & $3.7 \pm 0.1^{* * *}$ & $4.0 \pm 0.1^{*}$ \\
\hline Диаметр селезеночной артерии, мм & $6.0 \pm 0.1^{* * *}$ & $6.6 \pm 0.2$ & $6.4 \pm 0.1^{*}$ \\
\hline $\begin{array}{l}\text { Диаметр общей печеночной артерии, } \\
\text { мм }\end{array}$ & $5.7 \pm 0.2$ & $5.6 \pm 0.2$ & $5.9 \pm 0.2$ \\
\hline $\begin{array}{l}\text { Расстояние между центрами устьев } \\
\text { чревного ствола и верхней брыжееч- } \\
\text { ной артерии, мм }\end{array}$ & $19.4 \pm 0.4$ & $18.2 \pm 0.5$ & $19.0 \pm 0.5$ \\
\hline Длина основного ствола ВБА, мм & $201.4 \pm 3.9$ & $204.8 \pm 3.0$ & $206.4 \pm 2.9$ \\
\hline $\begin{array}{l}\text { Наибольший диаметр ВБА (началь- } \\
\text { ные отделы), мм }\end{array}$ & $7.8 \pm 0.1$ & $8 \pm 0.2$ & $8.2 \pm 0.2$ \\
\hline $\begin{array}{l}\text { Диаметр ВБА на уровне } 5 \text { мм дисталь- } \\
\text { нее устья подвздошно-ободочно- } \\
\text { кишечной артерии, мм }\end{array}$ & $5.2 \pm 0.1^{* *}$ & $4.9 \pm 0.1^{* * *}$ & $5.4 \pm 0.2$ \\
\hline 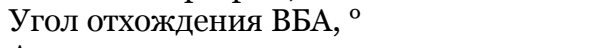 & $51.4 \pm 4 \cdot 3$ & $53.1 \pm 3.2^{* * *}$ & $63 \cdot 3 \pm 3.0^{*}$ \\
\hline $\begin{array}{l}\text { Аорто-мезентериальное расстояние, } \\
\text { мм }\end{array}$ & $15.1 \pm 1.2$ & $16.7 \pm 1.0$ & $18.2 \pm 1.3$ \\
\hline $\begin{array}{l}\text { Расстояние между центрами устьев } \\
\text { верхней брыжеечной и проксималь- } \\
\text { нее распложенной почечной артерии, } \\
\text { мм }\end{array}$ & $10.0 \pm 0.9$ & $12.1 \pm 1.3$ & $9.4 \pm 1.0$ \\
\hline $\begin{array}{l}\text { Расстояние между центрами устьев } \\
\text { верхней и нижней брыжеечных арте- } \\
\text { рий, мм }\end{array}$ & $74.6 \pm 2.3$ & $78.9 \pm 1.9$ & $74 \pm 1.6$ \\
\hline Длина основного ствола НБА, мм & $53.8 \pm 2.0$ & $58.0 \pm 2.8$ & $67 \cdot 3 \pm 4 \cdot 5^{*}$ \\
\hline $\begin{array}{l}\text { Наибольший диаметр НБА (началь- } \\
\text { ные отделы), мм }\end{array}$ & $3.9 \pm 0.1^{* *}$ & $4.3 \pm 0.1$ & $4.5^{ \pm 0.2^{*}}$ \\
\hline $\begin{array}{l}\text { Расстояние между центрами устьев } \\
\text { нижней брыжеечной и дистальнее } \\
\text { распложенной почечной артерии, мм }\end{array}$ & $63.7 \pm 2.3$ & $62.1 \pm 1.7^{* * * *}$ & $56.5^{ \pm 1.5^{*}}$ \\
\hline $\begin{array}{l}\text { Расстояние между центром устья } \\
\text { нижней брыжеечной артерии и би- } \\
\text { фуркацией аорты, мм }\end{array}$ & $39.8 \pm 1.7$ & $41.4 \pm 1.7^{* * *}$ & $45 \cdot 7 \pm 1.3^{*}$ \\
\hline
\end{tabular}

Наибольший диаметр чревного ствола, а также диаметры левой желудочной и печеночной артерий имеют достоверные различия только между крайними типами телосложения, в то время как значения диаметра ВБА на разных уровнях и наибольшего диаметра НБА статистически различаются во всех выделенных группах.
В процентном соотношении наибольшая разница характерна для диаметров ВБА и НБА. Так, наибольший диаметр НБА на $34.3 \%$, а диаметр ВБА на уровне 5 мм дистальнее устья подвздошно-ободочно-кишечной артерии на 30.2\% достоверно больше при гиперстеническом типе телосложения по сравнению с астеническим. В то же время разница в 
Морфометрическая характеристика брюшной аорты и ее непарных ветвей у мужчин в зависимости от типа телосложения по Пинье, $(\mathbf{M} \pm \mathbf{m})$

\begin{tabular}{|c|c|c|c|}
\hline \multirow[b]{2}{*}{ Морфометрические параметры } & \multicolumn{3}{|c|}{ Типы телосложения } \\
\hline & $\begin{array}{c}\text { Астенический } \\
\mathrm{n}=18\end{array}$ & $\begin{array}{l}\begin{array}{c}\text { Нормостенический } \\
\mathrm{n}=42\end{array} \\
\end{array}$ & $\begin{array}{c}\begin{array}{c}\text { Гиперстенический } \\
\mathrm{n}=54\end{array} \\
\end{array}$ \\
\hline $\begin{array}{l}\text { Диаметр аорты на уровне чревного } \\
\text { ствола, мм }\end{array}$ & $21.4 \pm 0.9^{* *}$ & $23.5 \pm 0.4$ & $23.8 \pm 0.4^{*}$ \\
\hline $\begin{array}{l}\text { Поперечный диаметр аорты на уровне } \\
5 \text { мм проксимальнее устьев почечных } \\
\text { артерий (либо устья проксимальнее } \\
\text { распложенной почечной артерии), мм }\end{array}$ & $19.4 \pm 0.9$ & $21.1 \pm 0.4$ & $21.8 \pm 0.3^{*}$ \\
\hline $\begin{array}{l}\text { Поперечный диаметр аорты на уровне } \\
\text { на уровне } 5 \text { мм проксимальнее бифур- } \\
\text { кации аорты, мм }\end{array}$ & $16.4 \pm 0.8$ & $17.8 \pm 0.3^{* * *}$ & $18.8 \pm 0.3^{*}$ \\
\hline Длина брюшного отдела аорты, мм & $145.9 \pm 2.9$ & $152.8 \pm 1.9$ & $155.0 \pm 2.2^{*}$ \\
\hline Длина чревного ствола, мм & $22.4 \pm 1.1^{* * *}$ & $26.9 \pm 0.9$ & $27.1 \pm 0.7^{*}$ \\
\hline $\begin{array}{l}\text { Наибольший диаметр чревного ство- } \\
\text { ла, мм }\end{array}$ & $7 \cdot 5^{ \pm 0.2^{* *}}$ & $8.1 \pm 0.2$ & $8.2 \pm 0.2^{*}$ \\
\hline Угол отхождения чревного ствола, ${ }^{\circ}$ & $29.0 \pm 1.8^{* *}$ & $40.3 \pm 2.6$ & $41.9 \pm 2.3^{*}$ \\
\hline $\begin{array}{l}\text { Диаметр левой желудочной артерии, } \\
\text { мм }\end{array}$ & $3.1 \pm 0.1^{* *}$ & $3.7 \pm 0.1$ & $3.9 \pm 0.1^{*}$ \\
\hline Диаметр селезеночной артерии, мм & $5.6 \pm 0.2^{* *}$ & $6.4 \pm 0.2$ & $6.5 \pm 0.1^{*}$ \\
\hline $\begin{array}{l}\text { Диаметр общей печеночной артерии, } \\
\text { мм }\end{array}$ & $5.6 \pm 0.3$ & $5 \cdot 5 \pm 0.2$ & $6.0 \pm 0.2$ \\
\hline $\begin{array}{l}\text { Расстояние между центрами устьев } \\
\text { чревного ствола и верхней брыжееч- } \\
\text { ной артерии, мм }\end{array}$ & $18 \pm 0.5$ & $18.9 \pm 0.4$ & $19.2 \pm 0.4$ \\
\hline $\begin{array}{l}\text { Длина основного ствола верхней } \\
\text { брыжеечной артерии, мм }\end{array}$ & $212.9 \pm 3.4^{* * *}$ & $197.0 \pm 3.1^{* * *}$ & $207.2 \pm 2.7$ \\
\hline $\begin{array}{l}\text { Наибольший диаметр верхней брыже- } \\
\text { ечной артерии (начальные отделы), } \\
\text { мм }\end{array}$ & $7.0 \pm 0.2^{* *}$ & $7.7 \pm 0.1^{* * *}$ & $8.6 \pm 0.2^{*}$ \\
\hline $\begin{array}{l}\text { Диаметр верхней брыжеечной арте- } \\
\text { рии на уровне } 5 \text { мм дистальнее устья } \\
\text { подвздошно-ободочно-кишечной ар- } \\
\text { терии, мм }\end{array}$ & $4.3 \pm 0.1^{* *}$ & $5.0 \pm 0.1^{* * * *}$ & $5.6 \pm 0.1^{*}$ \\
\hline $\begin{array}{l}\text { Угол отхождения верхней брыжееч- } \\
\text { ной артерии, }\end{array}$ & $33.0 \pm 3.6^{* * *}$ & $56.2 \pm 3.1$ & $64.3 \pm 2.7^{*}$ \\
\hline $\begin{array}{l}\text { Аорто-мезентериальное расстояние, } \\
\text { мм }\end{array}$ & $8.2 \pm 0.7^{* * *}$ & $17.0 \pm 1.2$ & $19.6 \pm 1.1^{*}$ \\
\hline $\begin{array}{l}\text { Расстояние между центрами устьев } \\
\text { верхней брыжеечной и проксималь- } \\
\text { нее распложенной почечной артерии, } \\
\text { мм }\end{array}$ & $8.4 \pm 1.3$ & $10.3 \pm 1.2$ & $11.4 \pm 0.9$ \\
\hline $\begin{array}{l}\text { Расстояние между центрами устьев } \\
\text { верхней и нижней брыжеечных арте- } \\
\text { рий, мм }\end{array}$ & $73.8 \pm 3.4$ & $77.6 \pm 1.4$ & $75.1 \pm 1.8$ \\
\hline $\begin{array}{l}\text { Длина основного ствола нижней бры- } \\
\text { жеечной артерии, мм }\end{array}$ & $50.2 \pm 2.5^{* *}$ & $57 \cdot 3 \pm 1.8$ & $65.7 \pm 3.9^{*}$ \\
\hline $\begin{array}{l}\text { Наибольший диаметр нижней брыже- } \\
\text { ечной артерии (начальные отделы), } \\
\text { мм }\end{array}$ & $3.5 \pm 0.1^{* *}$ & $4.4 \pm 0.1^{* * * *}$ & $4.7 \pm 0.1^{*}$ \\
\hline $\begin{array}{l}\text { Расстояние между центрами устьев } \\
\text { нижней брыжеечной и дистальнее } \\
\text { распложенной почечной артерии, мм }\end{array}$ & $63.7 \pm 2.6$ & $63.6 \pm 1.7^{* * *}$ & $57.1 \pm 1.5^{*}$ \\
\hline $\begin{array}{l}\text { Расстояние между центром устья } \\
\text { нижней брыжеечной артерии и би- } \\
\text { фуркацией аорты, мм }\end{array}$ & $40.2 \pm 2.8$ & $41.2 \pm 1.5$ & $44.3 \pm 1.3$ \\
\hline
\end{tabular}

значении диаметра левой желудочной артерии между крайними группами составляет 25.8\%, диаметра селезеночной артерии 16.1\%, а наибольшего диаметра чревного ствола всего 9.3\%.

Значения длины брюшного отдела аорты достоверно более выражены у гиперстени-

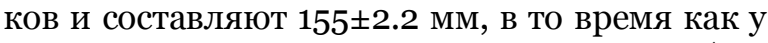
астеников - только 145.9 \pm 2.9 мм, таким образом разница между крайними формами достигает 9.1 мм. Длина чревного ствола, а также основного ствола НБА и ВБА также имеют выраженные типовые особенности. При этом, если значения первых двух параметров досто- 

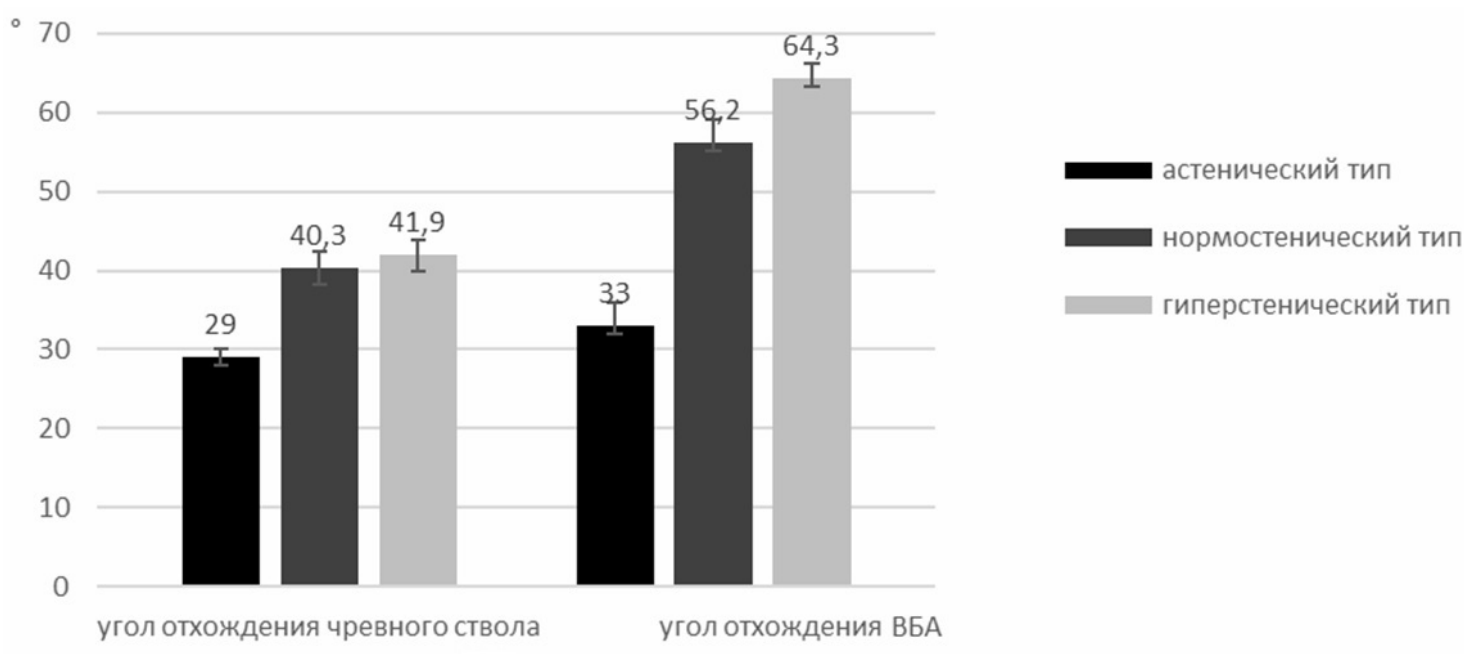

Рис. Средние значения изученных угловых параметров в зависимости от типа телосложения по Пинье.

верно больше у лиц гиперстенического типа, то значения длины основного ствола ВБА в среднем на 5.7 мм больше у астеников.

Расстояние между центрами устьев верхней брыжеечной и проксимальнее расположенной почечной артерий также различается между нормо- и гиперстениками (на 6.5 мм), а также между гипер- и астениками (на $6.6 \mathrm{~mm}$ ).

Аорто-мезентериальное расстояние достоверно различается между нормо- и астениками (на 8.8 мм) и между гипер- и астениками (на 11.4 мм).

В отличие от выделения групп по типу телосложения согласно классификации В.Н. Шевкуненко, в группах, систематизированных по значению индекса Пинье, различия наблюдаются по всем угловым параметрам. Так, угол отхождения чревного ствола в группе нормостеников в среднем на $11.3^{\circ}$ больше, чем у астеников (в процентном отношении - на 38.9\%), а у гиперстеников - на $12.9^{\circ}$, чем у астеников (на $44.5 \%$ больше). Различия в значениях угла отхождения ВБА между крайними типами телосложения по Пинье достигают $31.3^{\circ}$, что в процентном соотношении составляет 95\% (рис.).

При интерпретации полученных данных следует, в первую очередь, обратить внимание на то, что классификация В.Н. Шевкуненко отражает в большей степени линейные параметры тела, а индекс Пинье - еще и объемные (обхват груди, массу тела). Поэтому последний обеспечивает большее количество различий сравниваемых параметров, в том числе, зависящих от типа и степени развития абдоминальной жировой клетчатки. Вероятно, данное обстоятельство объясняет тот факт, что между типами телосложения по В.Н. Шевкуненко имеется меньше статистически достоверных различий по параметрам брюшной части аорты и ее непарных ветвей, а между конституциональными типами, выделенными с использованием индекса Пинье, имеются существенные достоверные различия по подавляющему большинству из изученных морфометрических параметров.

Сравнительный анализ линейных и угловых параметров брюшной аорты и ее непарных ветвей показал наличие достоверных различий у представителей разных типов телосложения. Наиболее информативные данные получены при использовании индекса Пинье.

Следует отметить, что знание различных вариантов строения брюшной аорты и ее морфометрических характеристик имеют не только анатомический интерес, но и клиническое значение при проведении ангиографии, оперативных вмешательств на органах гастроспленопанкреатодуоденальной зоны, химиоэмболизации и лимфодиссекции. Также данные сведения необходимы для лучшей и более точной интерпретации результатов рентгенологических методов исследований.

\section{Выводы}

1. Диаметр брюшной аорты на уровне чревного ствола не различается в зависимости от типа телосложения по В.Н. Шевкуненко, в то время как ее поперечный диаметр на других уровнях в среднем имеет разницу 1.3-1.7 мм между крайними группами. Длина брюшного отдела аорты имеет достоверные различия только между крайними формами телосложения - долихо- и брахиморфной. В группах, выделенных по индексу Пинье, диаметр брюшной аорты различается на всех уровнях. Разница в значении длины брюшного отдела аорты достигает 9.1 мм между гипер- и астениками.

2. При использовании индекса В.Н. Шевкуненко из изученных угловых параметров достоверно отличается только угол отхождения верхней брыжеечной артерии, а угол отхождения верхней брыжеечной артерии не имеет выраженных типовых особенно- 
стей. В группах, систематизированных по значению индекса Пинье, различия наблюдаются по всем угловым параметрам.

\section{Конфликт интересов}

Авторы заявляют об отсутствии конфликта интересов.

\section{Список литературы / References}

1. Анисимова Е.А., Лукина Г.А., Анисимов Г.И. Возрастная изменчивость тотальных размеров тела и типа телосложения женщин. Бюллетень медицинских Интернет-конференций. 2014; 4(6):918-21 [Anisimova EA, Lukina GA, Anisimov DI. Age variability of the total sizes of the body and constitution type of women. Bulletin of Medical Internet Conferences. 2014; 4(6):918-21] (in Russian).

2. Великорецкий А.Н. Оперативное лечение рака поджелудочной железы. М.: Издание 1 ММИ им. И.М. Сеченова; 1959: 176 [Velikoretskii A.N. Operativnoe lechenie raka podzheludochnoi zhelezy. Moscow: Izdanie 1 MMI im. I.M. Sechenova; 1959: 176] (in Russian).

3. Бархатов И.В, Бархатова Н.А. Эхографические способы диагностики и нормальные показатели кровотока в непарных висцеральных ветвях брюшной аорты. Вестник новых медицинских технологий. 2016; 23(4):299-306 [Barhatov IV, Barhatova NA. Sonographic methods of diagnosis and the indicators in norm of blood flow in unpaired visceral branches of the abdominal aorta. Journal of New Medical Technologies. 2016; 23(4):299-306] (in Russian).

4. Семиошко Н.В. Вариантная анатомия ветвления чревного ствола и прилежащих к нему лимфатических узлов. Педиатрический вестник Южного Урала. 2015; 1: 37-42 [Semioshko NV. Branching variant of the celiac trunk and surrounding lymph nodes. Pediatric Bulletin of the southern Urals. 2015; 1: 37-42] (in Russian).

5. Da Silveira LA, Silveira FBC, Fazan VPS. Arterial diameter of the celiac trunk and its branches: anatomical study. Acta Cirurgica Brasileira. 2009 Feb;24(1):43-7. doi: 10.1590/s010286502009000100009

6. Davis A, Holloway C, Lewandowski AJ, Ntusi $N$, Nethononda RM, Pitcher A, et al. Diameters of the normal thoracic aorta measured by cardiovascular magnetic resonance imaging; correlation with gender, body surface area and body mass index. Journal of Cardiovascular Magnetic Resonance. 2013 Jan;15(S1). doi: 10.1186/1532-429x-15-s1-e77

7. Gangam RR, Lakmala $V$. A morphometric study of branching pattern of inferior mesenteric artery. Int. J. Pharm. Bio. Sci. 2016; 7(2):19-25.

8. Ghodasara N, Liddell R, Fishman EK, Johnson $P T$. High-Value Multidetector CT Angiography of the Superior Mesenteric Artery: What Emergency
Medicine Physicians and Interventional Radiologists Need to Know. RadioGraphics. 2019 Mar;39(2):559-77. doi: 10.1148/rg.2019180131

9. Joh JH, Ahn H-J, Park H-C. Reference Diameters of the Abdominal Aorta and Iliac Arteries in the Korean Population. Yonsei Medical Journal. 2013;54(1):48-54. doi: 10.3349/ymj.2013.54.1.48

10. Länne T, Sonesson B, Bergqvist D, Bengtsson $H$, Gustafsson D. Diameter and compliance in the male human abdominal aorta: Influence of age and aortic aneurysm. European Journal of Vascular Surgery. 1992 Mar;6(2):178-84. doi: 10.1016/s0950-821x(05)80237-3

11. Malnar D, Klasan $G$, Miletić D Bajek $S$, Vranić TS, Arbanas J, Bobinac D, Coklo M. Properties of the Celiac Trunk - Anatomical study. Coll. Antropol. 2010 Sep;34(3):917-21.

12. Pivawer $G$, Haller JO, Rabinowitz SS, Zimmerman $D L$. Superior mesenteric artery syndrome and its ramifications. CMIG Extra: Cases. 2004 Jan;28(1):8-10. 10.1016/j.compmedimag.2003.09.006

13. Sariosmanoglu N, Ugurlu B, Karacelik M, Tuzun E, Yorulmaz I, Manisali M, et al. A Multicentre Study of Abdominal Aorta Diameters in a Turkish Population. Journal of International Medical Research. 2002 Feb;30(1):1-8. doi: 10.1177/147323000203000101

14. Sinkeet $S$, Mwachaka $P$, Muthoka $J$, Saidi $H$. Branching Pattern of Inferior Mesenteric Artery in a Black African Population: A Dissection Study. ISRN Anatomy. 2013;2013:1-4. doi: 10.5402/2013/962904

15. Solberg S, Forsdahl SH, Singh K, Jacobsen BK. Diameter of the Infrarenal Aorta as a Risk Factor for Abdominal Aortic Aneurysm: The Tromsø Study, 1994-2001. European Journal of Vascular and Endovascular Surgery. 2010 Mar;39(3):2804. doi: 10.1016/j.ejvs.2009.10.017

16. Songür A, Toktaş M, Alkoç O, Acar T, Uzun İ, Baş $O$, et al. Abdominal Aorta and Its Branches: Morphometry - Variations In Autopsy Cases. European Journal of General Medicine. $2010 \mathrm{Jul}$ 12;7(3):321-5. doi: 10.29333/ejgm/82876

17. Tanka $M$, Abazaj $E$. Anatomical variations of celiac trunk anatomy and their clinical importance. Int. J. of science and research. 2013; 4(12):12-4.

18. White RD, Weir-McCall JR, Sullivan CM, Mustafa $S A R$, Yeap PM, Budak MJ, et al. The Celiac Axis Revisited: Anatomic Variants, Pathologic Features, and Implications for Modern Endovascular Management. $\quad$ RadioGraphics. 2015 May;35(3):879-98. doi: 10.1148/rg.2015140243

19. Winston $C B$, Lee NA, Jarnagin WR, Teitcher $J$, DeMatteo RP, Fong $Y$, et al. CT Angiography for Delineation of Celiac and Superior Mesenteric Artery Variants in Patients Undergoing Hepatobiliary and Pancreatic Surgery. American Journal of Roentgenology. 2007 Jul;189(1):W13-9. doi: 10.2214/ajr.04.1374

$$
\begin{gathered}
\text { Поступила в редакцию 21.02.2019 } \\
\text { Принята в печать 30.04.2019 }
\end{gathered}
$$

Received 21.02.2019 Accepted 30.04.2019

Для циитирования: Быков П.М., Гайворонский И.В., Гайворонская М.Г., Синенченко Г.И. Сравнительная характеристика морфометрических параметров брюшной аорты и ее непарных ветвей у мужчин с различным типом телосложения. Журнал анатомии и гистопатологии. 2019; 8(2): 15-21. doi: 10.18499/2225-7357-2019-8-2-15-21

For citation: Bykov P.M., Gaivoronskii I.V., Gaivoronskaya M.G., Sinenchenko G.I. Comparative characteristics of the morphometric parameters of the abdominal aorta and its unpaired branches in men with different body types. Journal of Anatomy and Histopathology. 2019; 8(2): 15-21. doi: 10.18499/2225-7357-2019-8-2-15-21 